\title{
Diphtheritic polyneuropathy: a clinical study and comparison with Guillain-Barré syndrome
}

\author{
Inara Logina, Michael Donaghy
}

\begin{abstract}
Objectives and Methods-Clinical features of 50 adults with diphtheritic polyneuropathy (DP) were studied in Riga, Latvia and compared with 21 patients with GuillainBarré syndrome (GBS).
\end{abstract}

Results-Neurological complications occurred in $15 \%$ of patients admitted to hospital with diphtheria and usually after severe pharyngeal infection. Bulbar dysfunction occurred in $98 \%$ of patients with DP and only $10 \%$ of patients with GBS. Limb weakness was mild or absent in $30 \%$ of patients with DP. Ventilation dependent respiratory failure occurred in $20 \%$ of patients with DP. The first symptoms of DP occurred 2-50 days after the onset of local diphtheria infection. Neurological deterioration in DP continued for a median of 49 (range 15-83) days and improvement started 73 (range 20-115) days after onset. In $66 \%$ of patients with DP, the neuropathy was biphasic with a secondary worsening after 40 days. By contrast patients with GBS worsened for only 10 days on average (range $2-28$ days) and improved after 21 (range 4-49) days. Eight patients with DP died, four from severe cardiomyopathy and four from multiple diphtheritic organ failure. Prolonged distal motor latencies (DMLs) were common to both DP and GBS, and more pronounced than motor conduction slowing. Limb symptoms continued after 1 year in $80 \%$ of the patients with DP, $6 \%$ were unable to walk independently, but independent respiratory and bulbar function had returned in all survivors. By comparison no patients with GBS died and none were severely disabled after 1 year. No death, in patients with DP occurred after antitoxin on days 1 or 2 after onset of diphtheria symptoms, whereas identical rates of death and peak severity of DP were seen both in those who received antitoxin on days 3-6 and those who did not receive it at all.

Conclusion-Diphtheric polyneuropathy is much more likely than GBS to have a bulbar onset, to lead to respiratory failure, to evolve more slowly, to take a biphasic course, and to cause death or long term disability. Antitoxin seems ineffective if administered after the second day of diphtheritic symptoms.

(F Neurol Neurosurg Psychiatry 1999;67:433-438)

Keywords: diphtheritic polyneuritis; clinical features; outcome; diphtheritic antitoxin; Guillain-Barré syndrome
The recent resurgence of diphtheria in central and eastern Europe ${ }^{1}$ has provided a modern day opportunity to study the acute demyelinating polyneuropathy which has long been recognised as the most common severe complication of diphtheria infection. ${ }^{2-4}$ Diphtheritic polyneuropathy (DP) affecting the limbs usually follows faucal infection and earlier paralysis of the palate. Palatal paralysis and paralysis of accommodation do not tend to follow antecedent cutaneous infections, and probably reflect the regional effects of locally produced toxin in faucal infection. ${ }^{5}{ }^{6}$ Neuropathy affects the limbs or diaphragm later, up to 3 months after the onset of the diphtheria. Histology shows segmental demyelination of peripheral nerves, with additional axonal degeneration in the most severe cases. ${ }^{7-9}$

Observations, mainly on children at the turn of the century, showed that DP followed 20\%$27 \%$ of infections. ${ }^{10}$ A similar incidence of neurological complications was found in young adults during the second world war, with palatal paralysis in $15 \%$ and polyneuropathy in $11 \%{ }^{4}$ These large studies antedated modern understanding of the pathogenesis and electrophysiological diagnosis of acute paralysis, patients were unlikely to survive respiratory failure, and antibiotics were not used. Recent detailed neurological reports on DP in the English literature have tended to focus on single cases or small numbers. ${ }^{911}{ }^{12}$ The benefits of early administration of modern diphtheria antitoxins remain unstudied. However, the annual occurrence of paralysis in diphtheria increased from $13.6 \%$ to $18.9 \%$ after the introduction of antitoxin in 1894, in Rolleston's (1904) analysis of up to 7000 cases annually. Furthermore, the likelihood of severe paralysis seemed to be reduced only if antitoxin had been administered within the first 2 or 3 days of infection. ${ }^{4}{ }^{10}$

A fall of immunity in the adult population has resulted in a spectacular return of diphtheria in eastern European countries, such as Latvia, since 1993, where it had been successfully controlled previously. ${ }^{13}$ Occasionally, diphtheria had been encountered in Latvia from 1986 onwards with the epidemic starting in $1994 .{ }^{15-17}$ Adults vaccinated in childhood do not continue to have sufficient immunity to protect against diphtheria once this infection returns to a population. Ten per cent of randomly selected Danish men born 1950-59 had lost protection against diphtheria. ${ }^{18}$ In the United States $40 \%$ to $50 \%$ of persons older than 30 years are susceptible to diphtheria ${ }^{19}$ and $22 \%$ of previously vaccinated Danish adults lack protective concentrations of 
antitoxin. ${ }^{20}$ As a result of this resurgence of diphtheria, mass reimmunisation of adults was undertaken in Latvia during 1997. Thus DP is a particular diagnostic possibility in middle aged patients with acute polyneuropathy despite diphtheria vaccination in their childhood. We studied the clinical evolution of polyneuropathy, and the influence of antitoxin, during this recent outbreak of diphtheria in Latvia. Patients with DP were compared with patients with GBS encountered in the same hospital; GBS has a relatively stable incidence of 1 to 2/100 000 population. ${ }^{21} 22$

\section{Methods}

PATIENT POPULATION

Fifty patients with DP and 21 patients with GBS were studied during admission to P Stradin's Hospital from 1993 to 1997. We excluded patients with systemic immunological disorders, neoplasms, suspected brainstem encephalitis, neuroborreliosis, severe diabetes, or porphyria. The diagnosis of GBS was according to standard guidelines ${ }^{23}$ : symmetric progressive motor weakness and areflexia of more than one limb cresting by 4 weeks. One patient with GBS had a preceding sore throat, and throat swab cultures for diphtheria in this and four other patients with GBS were negative. Three patients with GBS were treated with IVIg and 11 with plasma exchange within the first 2 weeks of neurological symptoms.

Definite and probable cases of DP were diagnosed according to World Health Organisation (WHO) criteria ${ }^{24}$ after confirmation of localised acute diphtheria (tonsillar, palatal, pharyngeal, nasal, lingual, or combined) in 48 patients who subsequently developed multiple cranial or limb neuropathy within 6 weeks. Two unsuspected additional cases were included from early in the epidemic after developing diagnostic clinical features of DP. The patients with DP exhibited acute laryngitis, nasopharyngitis, or tonsillitis with pseudomembranes and were defined as having severe toxic diphtheria if there was neck oedema, toxic collapse, acute renal failure, or myocarditis. Toxigenic strains of Corynebacterium diphtheriae were isolated from throat swabs in 38 patients. Increased titres of diphtheria antibodies in serum samples were detected in seven other patients. Another five patients were diagnosed as clinically probable cases including two with typical necropsy findings.

\section{CLINICAL ASSESSMENT}

Leg weakness and disability were related to a seven point functional scale ${ }^{25}{ }^{26}: 0=$ normal; $1=$ minor symptoms and signs but capable of work manually; $2=$ able to walk $10 \mathrm{~m}$ without support but incapable of manual work; $3=$ able to walk $\geqslant 10 \mathrm{~m}$ with a stick or support; $4=$ unable to walk $10 \mathrm{~m}$ even with support; $5=$ requiring assisted ventilation; $6=$ dead. Bulbar function was expressed on a four point scale: $0=$ normal; $1=$ minor symptoms without dysphagia; $2=$ moderate dysphagia, nasal voice, or palatal paresis; $3=$ severe dysphagia requiring a nasogastric tube. Ocular motor and facial paralyses were graduated as: $0=$ normal;
$1=$ minimal symptoms or signs; $2=$ severe paresis or paralysis. Sensory symptoms were graded: $0=$ none; $1=$ minor without affecting movement, mood, or sleep; $2=$ intrusive and needing symptomatic therapy. Respiratory muscle function was graded: $0=$ normal; $1=$ mild to moderate dyspnoea without requiring assisted ventilation; $2=$ needing assisted ventilation. A global estimate of the degree of severity of each patient's neuropathy was derived. Group I (mild) patients had 0 to 2 leg motor function, or grade 0 to 1 bulbar function, or grade 0 to 1 of sensory symptoms, and grade 0 respiratory function. Group II (moderately severe) patients had grade 3 leg motor function, or grade 2 bulbar function, or grade 1 or 2 sensation, or grade 1 respiratory function. Group III (severe) patients had grade 4 or 5 leg motor function, or grade 3 bulbar function, or grade 2 sensation, or grade 2 respiratory function. This grading system provides a broad comparison of patients with different patterns of neurological involvement, but cannot equally weight different regional distributions of involvement.

Neurological assessment was performed on neurological admission, weekly during admission to hospital, and on discharge. Fifteen patients with GBS and 41 patients with DP were reassessed after discharge after intervals of 6 to 18 months: 34 by re-examination, 17 by postal questionnaire, and five by reports from other neurologists in outlying regions.

\section{ELECTROPHYSIOLOGICAL STUDIES}

Forty one electrophysiological studies in 37 patients with DP and 20 in 19 patients with GBS were performed at various stages of paralysis. Distal motor latencies (DMLs) and motor conduction velocities (MCVs) in the median, ulnar, tibial, and peroneal nerves were measured using a Neuropack-II (Nihon Kohden, Japan). Normal values for DMLs were $4.4,3.4$, and $5.8 \mathrm{~ms}$ in median, ulnar, and tibial nerves. Normal MCV exceeded $45 \mathrm{~m} / \mathrm{s}$ in the arms and $40 \mathrm{~m} / \mathrm{s}$ in the peroneal nerve.

\section{Results}

PATIENT PROFILE

Eighty per cent of patients with DP were aged 41 to 60 years and most (84\%) were urban dwellers. Many patients with GBS were younger, with $52 \%$ from rural populations. Fifty two per cent of patients with DP and 71\% of patients with GBS were male. Nine (43\%) of the patients with GBS reported antecedent events between 9 to 30 days (mean 23) before their first neuropathic symptoms, nasal catarrh in eight, sore throat alone in one, which resolved before onset of neuropathy. None had diphtheritic pseudomembrane in the pharynx and all five tested patients were negative on throat swab culture for $C$ diphtheriae. In the DP group occurrence of neurological complications was related to the severity of the diphtheritic infection. Thirty patients $(60 \%)$ had severe forms of diphtheria with systemic toxicity and neck oedema. Seventeen (34\%) did not receive diphtheritic antitoxin because 
Table 1 Administration of antitoxin and peak severity of diphtheria polyneuropathy

\begin{tabular}{lclllr}
\hline $\begin{array}{l}\text { Day of antitoxin } \\
\text { administration }\end{array}$ & $\begin{array}{l}\text { Total No of } \\
\text { patients }\end{array}$ & Deaths & $\begin{array}{l}\text { Severe } \\
\text { Disability } \\
\text { (grade III) }\end{array}$ & $\begin{array}{l}\text { Moderate } \\
\text { Disability } \\
\text { (grade II) }\end{array}$ & $\begin{array}{l}\text { Mild disability } \\
\text { (grade I) }\end{array}$ \\
\hline 1st-2nd & $5(100 \%)$ & $0(0)$ & $2(40)$ & $0(0)$ & $3(60)$ \\
3rd-6th & $28(100 \%)$ & $5(18)$ & $7(25)$ & $5(18)$ & $11(39)$ \\
Did not receive & $17(100 \%)$ & $3(18)$ & $4(24)$ & $4(24)$ & $6(35)$ \\
\hline
\end{tabular}

Data are No of patients (\%).

they consulted late, including nine $(18 \%)$ who first presented with polyneuropathy.

COURSE OF DISEASE

The neurological manifestations of DP and GBS generally developed in different sequences. Typically DP developed over two phases. The first DP symptom was bulbar in 49 patients a median of 10 (range 2-50) days after onset of localised throat diphtheria. Initial improvement of bulbar symptoms occurred at 30 (range 3-98) days after onset of neurological symptoms. In 19 secondary deterioration of bulbar function occurred 40 (range 17-54) days from onset. In 14 others limb symptoms either commenced or worsened while the bulbar symptoms were already recovering. Limb symptoms occurred in 45 patients with DP and appeared at 37 (range 12-63) days; limb symptoms never preceded bulbar symptoms except in one patient with limb involvement alone. Peak severity of DP was reached 49 (range 15-83) days after onset of diphtheria and improvement began at 73 (range 20-115) days. By contrast, neurological deterioration in GBS peaked at 10 (range 2-28) days, improved at 21 (range 4-49) days, and always followed a monophasic course. By contrast DP was biphasic in 33 patients, with four requiring intubation and ventilation during the secondary phase only.

ADMINISTRATION OF DIPHTHERITIC ANTITOXIN

The relation of antitoxin administration (horse hyperimmune serum) to the severity of DP was analysed (table 1). Seventeen (34\%) patients with DP did not receive antitoxin, because they consulted beyond 1 week from the onset of diphtheria and could represent a group with initially less acutely toxic diphtheria. Five $(10 \%)$ received antitoxin within 2 days of onset, and $28(59 \%)$ on the 3 rd to the 6 th day. In those who received antitoxin early (first 2 days) there were no deaths, but two of five patients became severely weakened at peak severity. The rates of death and peak severity were closely similar in the group not receiving antitoxin, and in those receiving antitoxin 3 to 6 days into diphtheria.

CLINICAL FEATURES AT TIME OF MAXIMUM SEVERITY

Limb weakness was present in all patients with GBS, and $91 \%$ of them became unable to walk unaided (table 2). Twelve per cent of patients with DP developed no limb weakness, and only $48 \%$ of patients with DP became unable to walk unaided. Achilles tendon reflexes were lost in $78 \%$ patients with DP, usually being retained in those with pure bulbar involvement. Bulbar paralysis affected $98 \%$ of patients with
DP with $32 \%$ requiring nasogastric tube nutrition. By contrast only $10 \%$ of patients with GBS had bulbar dysfunction. Facial paresis and limb sensory disturbances occurred similarly in both DP and GBS. Twenty per cent of patients with DP required artificial ventilation for an average of 27 (range 3-64) days and another $10 \%$ had milder respiratory muscle weakness. Only one patient with GBS had mild respiratory disturbance and none in this series required ventilation. Although $36 \%$ of patients with DP showed blood pressure swings or cardiac arrhythmia, autonomic neuropathy could not be distinguished from diphtheritic cardiomyopathy. Disturbed bladder function occurred in $34 \%$ of patients with DP but only $5 \%$ of patients with GBS. Six per cent of patients with DP had visual disturbance due to optic nerve lesions with impaired visual acuity, pale optic discs, and delayed visual evoked potentials. Protein concentrations in CSF were increased $(>0.45 \mathrm{~g} / \mathrm{l})$ in nine of 18 patients with GBS and all six patients with DP (mean 0.8 $\mathrm{g} / \mathrm{l})$.

Grade 1 (mild) peak severity was more common in DP (table 2) but grade III severity was equally common in DP and GBS. All of the patients with severe DP had initial severely toxic local diphtheria and only two had received diphtheria antitoxin during the first 2 days. All 21 severely affected patients with DP had failure of other organs. Sixty four per cent of patients with DP had clinical or electrophysiological evidence of myocarditis, $38 \%$ had pneumonia, and $6 \%$ had thromboembolism. Organ failure was not a feature of the patients with GBS.

MOTOR NERVE CONDUCTION STUDIES

Distal motor latencies (DMLs) were similarly prolonged in DP and GBS at all stages of the diseases (table 3). Motor nerve conduction velocities (MCVs) were less markedly slowed, particularly in the early part of the clinical

Table 2 Neurological signs at peak severity

\begin{tabular}{|c|c|c|c|}
\hline & & $\begin{array}{l}G B S(n=21) \\
n(\%)\end{array}$ & $\begin{array}{l}D P(n=50) \\
n(\%)\end{array}$ \\
\hline \multicolumn{4}{|l|}{ Limb weakness: } \\
\hline \multirow[t]{2}{*}{ Mild } & Grade 1 & $0(0)$ & $9(18)$ \\
\hline & Grade 2 & $2(10)$ & $8(16)$ \\
\hline Moderate & Grade 3 & $9(43)$ & $7(14)$ \\
\hline \multirow[t]{3}{*}{ Severe } & Grade 4 & $10(48)$ & $10(20)$ \\
\hline & Grade 5 & $0(0)$ & $7(14)$ \\
\hline & Grade 6 & $0(0)$ & $3(6)$ \\
\hline \multicolumn{4}{|c|}{ Bulbar dysfunction: } \\
\hline Mild & Grade 1 & $1(5)$ & $12(24)$ \\
\hline Moderate & Grade 2 & $1(5)$ & $21(42)$ \\
\hline Severe & Grade 3 & $0(0)$ & $16(32)$ \\
\hline \multicolumn{4}{|c|}{ Ocular motor paralysis: } \\
\hline Mild & Grade 1 & $1(5)$ & $10(20)$ \\
\hline Severe & Grade 2 & $0(0)$ & $5(10)$ \\
\hline \multicolumn{4}{|l|}{ Facial paresis: } \\
\hline Mild & Grade 1 & $4(19)$ & $5(10)$ \\
\hline Severe & Grade 2 & $0(0)$ & $0(0)$ \\
\hline \multicolumn{4}{|c|}{ Respiratory muscle weakness: } \\
\hline Mild & Grade 1 & $1(5)$ & $5(10)$ \\
\hline Severe & Grade 2 & $0(0)$ & $10(20)$ \\
\hline \multicolumn{4}{|l|}{ Sensory symptoms: } \\
\hline Mild & Grade 1 & $8(38)$ & $19(38)$ \\
\hline Severe & Grade 2 & $2(48)$ & $23(46)$ \\
\hline \multicolumn{4}{|c|}{ Autonomic involvement: } \\
\hline Cardiovascular & & $3(14)$ & $18(36)$ \\
\hline Bladder & & $1(5)$ & $17(34)$ \\
\hline
\end{tabular}

GBS=Guillain-Barré syndrome; $\mathrm{DP}=$ diphtheria polyneuropathy. 
Table 3 Motor Nerve conduction studies

\begin{tabular}{llclrl}
\hline Nerve & Phase & $\begin{array}{l}\text { No of } \\
\text { patients }\end{array}$ & $\begin{array}{l}\text { DP(mean } \\
D M L(S D))\end{array}$ & $\begin{array}{c}\text { No of } \\
\text { patients }\end{array}$ & $\begin{array}{l}\text { GBS (mean } \\
\text { DML (SD)) }\end{array}$ \\
\hline Median nerve & Evolution & 3 & $5.2(0.35)$ & 3 & $5.5(0.5)$ \\
& Plateau & 6 & $6.5(1.4)$ & 5 & $6.8(0.9)$ \\
Ulnar nerve & Recovery & 32 & $5.8(0.2)$ & 15 & $5.9(0.3)$ \\
& Evolution & 3 & $4.0(0.2)$ & 3 & $3.6(0.3)$ \\
Tibial nerve & Plateau & 6 & $4.0(0.4)$ & 5 & $4.8(0.6)$ \\
& Recovery & 32 & $4.2(0.1)$ & 12 & $4.1(0.2)$ \\
& Evolution & 3 & $6.8(0.3)$ & 3 & $6.2(0.8)$ \\
& Plateau & 6 & $8.6(1.5)$ & 5 & $8.5(0.8)$ \\
& Pecovery & 32 & $2.5(0.3)$ & 15 & $8.5(0.6)$ \\
\hline
\end{tabular}

GBS=Guillain-Barré syndrome; $\mathrm{DP}=$ diphtheria polyneuropathy; $\mathrm{DML}=$ distal motor latency.

course of DP and GBS, and slowing tended to persist during recovery. Prolonged median nerve DMLs and slowed MCVs were present in some patients more than 100 days after onset of DP and after 1.5 years in one patient.

OUTCOME

For both DP and GBS the proportion of patients with only mild manifestations (grade I) had increased considerably by discharge from hospital and correspondingly, the numbers with severe manifestations (grade III) had decreased, but more so in the GBS group (table 4). At the time of discharge $10(24 \%)$ surviving patients with DP were unable to walk independently, compared with $13(62 \%)$ patients with GBS. The average duration of hospital admissions for DP was 34.4 (range 7-101) days and for GBS 19.9 (range 8-33) days. Follow up at 1 year was possible in 15 patients with GBS and 34 patients with DP, both showing further improvement. However, three $(20 \%)$ patients with GBS and $14(41 \%)$ patients with DP were not able to return to manual work although able to walk. For those followed up at 1 year, two $(6 \%)$ surviving patients with DP and two (13\%) patients with GBS still required walking aids. Other limb symptoms (numbness, paraesthesias, weakness) continued after 1 year in $80 \%$ of patients with DP. Eight (16\%) of the patients with DP died, seven while in hospital, on average 70 (range 29-93) days from the onset of diphtheria. Deaths were attributed to cardiac arrhythmias (four) after exertion, and to severe septic complications (four) variously combined with pneumonia, renal failure, myocarditis, and pulmonary embolism.

Table 4 Outcome at discharge, and at 1 year

\begin{tabular}{lcc}
\hline & $G B S n(\%)$ & $D P n(\%)$ \\
\hline Peak severity & $21(100)$ & $50(100)$ \\
Grade 1 & $2(10)$ & $20(40)$ \\
Grade 2 & $9(42)$ & $9(18)$ \\
Grade 3* & $10(48)$ & $16(32)$ \\
Death & $0(0)$ & $5(10)$ \\
At discharge & $21(100)$ & $45(100)$ \\
Grade 1 & $8(38)$ & $33(73)$ \\
Grade 2 & $12(57)$ & $2(4)$ \\
Grade 3* & $1(5)$ & $8(18)$ \\
New deaths & $0(0)$ & $2(4)$ \\
At 1 year & $15(100)$ & $34(100)$ \\
Grade 1 & $13(87)$ & $31(91)$ \\
Grade 2 & $2(13)$ & $2(6)$ \\
Grade 3* & $0(0)$ & $0(0)$ \\
New deaths & $0(0)$ & $1(3)$ \\
\hline
\end{tabular}

GBS=Guillain-Barré syndrome; $\mathrm{DP}=$ diphtheria polyneuropathy.

${ }^{\star}$ Grade 3 excludes deaths.
Discussion

Diphtheritic polyneuropathy in Latvia affected males and females equally, was most prevalent in urban dwellers aged 40 to 60 years, and no patients with DP were encountered aged under 18 years. This population of 50 patients with DP studied at a neurological centre in Riga can be related to the overall diphtheria epidemic in Latvia. They comprise about half of all known patients with DP in Latvia during this period. ${ }^{15}$ Data from the National Environmental Health Centre registered 731 cases of diphtheria in Latvia in 1994-6, 57\% adults aged 30-50. During this period in the whole of Latvia we are aware of a total of 111 patients with DP. Thus at least $15.2 \%$ of all patients diagnosed with diphtheria developed polyneuropathy. Polyneuropathy is generally regarded as being uncommon in mild diphtheritic infection, but occurs in about $10 \%$ of cases of average severity and in up to $75 \%$ of severe cases. ${ }^{3}$ Our present day Latvian data confirm that polyneuropathy is far more likely to develop after severe localised diphtheritic infection, including bull neck and those with toxic shock. ${ }^{232728}$

Immediate administration of horse serum antitoxin has been regarded as a mainstay of diphtheria treatment after its introduction in $1894,{ }^{10}$ but it is unclear for how long after the onset of diphtheria infection such treatment will be still beneficial. ${ }^{24}$ Serum sickness can occur in up to $10 \%{ }^{3}$ No formal clinical trials of antitoxin administration have been performed, but the incidence of paralysis only seems to be reduced if antitoxin is administered during the first 2 or 3 days of diphtheritic infection. ${ }^{410}$ Our contemporary retrospective data also provide no evidence that antitoxin administered after day 2 of infection modified the severity of neuropathy or prevented deaths. Our data suggest that antitoxin administration on days $0-2$ prevents death although cases of severe neuropathy still occur.

The main clinical features of diphtheritic polyneuropathy described in present day texts $^{2} 32930$ followed experience during the epidemics at the turn of the century and during the second world war. ${ }^{4-610}$ Recent descriptions of DP are based on single cases or small numbers. ${ }^{11}{ }^{31-33}$ Our analysis of 50 patients with contemporaneous DP shows that bulbar and respiratory involvement continue to predominate, in $98 \%$ and $30 \%$ of patients respectively. Present day endotracheal intubation, assisted ventilation, and nasogastric tube feeding ensure greater survival and were required in 32\% of our patients with DP. Although $16 \%$ of our patients with DP died, this was not usually a direct consequence of bulbar or respiratory muscle failure. There are no estimates of respiratory failure in diphtheritic polyneuropathy before the introduction of endotracheal ventilation and the overall death rate of $2 \%-4 \%{ }^{4}$ in diphtheritic infection doubtless included many non-neuropathic complications. Optic neuropathy, occurring in three $(6 \%)$ of our patients, is not a generally recognised feature of $\mathrm{DP}$, but such visual disturbances have been described previously. ${ }^{10}$ Nerve conduction studies were not available to study earlier epidemics 
of DP. A few electrophysiological studies have been reported more recently, generally showing reduced motor nerve conduction velocity, initially mild, and still decreasing while clinical recovery begins. ${ }^{9}{ }^{12} 34$ Our data confirm these findings and did not disclose any electrodiagnostic differences between DP and GBS.

A novel finding was of a secondary deterioration in DP symptoms in $66 \%$. In $38 \%$ the bulbar symptoms deteriorated afresh after initial partial recovery, and ventilation first became necessary during this second bulbar phase in some. In $28 \%$, limb symptoms started or continued to worsen while bulbar symptoms had started recovering. This biphasic fluctuation in the course of disease suggests that diphtheria toxin locally affects nerve endings in bulbar muscles at an early stage, before systemic dispersion of the toxin produces late effects on limb or bulbar nerves. In $10 \%$ of patients with DP with bulbar paralysis there were no limb symptoms and Achilles tendon jerks were preserved; no secondary deterioration occurred and we suspect that these patients exhibited the local bulbar effects of diphtheria toxin without any significant systemic dispersion.

The particular clinical features differentiating DP from GBS are firstly the high prevalence of bulbar and respiratory muscle dysfunction at a time of little or no limb involvement; secondly, the evolution of the neuropathy for much longer than 4 weeks; thirdly, the preceding sore throat rather than catarrhal illness; and fourthly, the simultaneous involvement of other organ systems. Both cause similar patterns of limb involvement. Most DP started within the first 2 weeks after local infection, a similar time interval to that separating GBS from its antecedent infections. Our 21 patients with GBS showed less frequent facial, bulbar, respiratory, and ocular motor involvement, commoner sensory disturbance, were generally younger than in larger series, and none died. ${ }^{2} 212235-38$ The initial differential diagnosis from GBS is difficult for those occasional patients with DP without bulbar palsy. Basically, DP limb symptoms evolve for longer than GBS, last longer, and are more likely to result in chronic disability; only $20 \%$ were completely healthy after 1 year. ${ }^{35}{ }^{38}$ At 1 year $6 \%$ of our patients with DP and $13 \%$ of patients with GBS were unable to walk independently; previous series show that $16 \%$ of patients with GBS cannot walk independently at 1 year. ${ }^{39}$ Of those we were able to follow up, $20 \%$ of patients with GBS and $41 \%$ of patients with DP had been unable to return to manual work; but we cannot discriminate between those incapable of manual work and those whose illness had simply transferred them to the unemployment register.

Toxic failure of systemic organs is the major influence on survival from diphtheria now that endotracheal intubation prevents death due to bulbar or respiratory muscle failure. Half to two thirds have evidence of cardiac dysfunction, clinically apparent myocarditis develops in $10 \%-25 \%$, and pneumonia occurs in more than half of fatal cases of diphtheria. ${ }^{3}$ Combinations of DP and myocarditis were frequent, occurring in $64 \%$ of our patients, and nephritis $(18 \%)$ and pneumonia $(38 \%)$ were also common. We confirmed that diphtheritic myocarditis is the major cause of death in diphtheria ${ }^{41}{ }^{42}$ and severe pulmonary complications are also found, particularly in adults. ${ }^{43}$ It can be difficult to discriminate between the autonomic cardiovascular disturbances in DP and the myocarditis. Mortality from diphtheria generally increases with severity of local disease and if antitoxin is not administered immediately after the onset of local disease. Our study showed a mortality of $16 \%$ in DP, reflecting the initial severity of local diphtheria. The death rate is highest among patients with "bull neck" diphtheria or other toxic forms, which are predictors of cardiac, neuropathic, or other complications. ${ }^{1324282943-45}$ The overall case fatality rate for diphtheria was $2.4 \%$ in the $1940 \mathrm{~s}^{4}$ and remained at $2 \%-3 \%$ in the Russian outbreak of the 1990 s. $^{1}$

We thank Mrs E Vesma and Mrs J Wilkinson for preparing the manuscript, Dr I Kravale for the neurophysiological studies, and the British Council for a travel grant.

1 Rakhmanova AG, Lumio J, Groundstroem K, et al. Diphtheria outbreak in St Petersburg: clinical characteristics of 1860 adult patients. Scand $\mathcal{F}$ Infect Dis 1996;28:3740 .

2 Donaghy M. Disorders of peripheral nerves. In: Walton J, ed. Brain's diseases of the nervous system. 10th ed. Oxford: ed. Brain's diseases of the nervous system.

3 Holmes RK. Ch 144. Diphtheria, other corynebacterial infectious and anthrax. In: Fauci A, Braunwald E, sselbacher K, et al, eds. Harrison's Principles of internal medicine. XIII. New York: McGraw-Hill, 1997:892-9.

4 Palley RG, Truelove SC. Diphtheria in the Army in the United Kingdom. A study of its complications. Fournal of the Royal Army Medical Corps 1948;90:109-16.

5 Walshe FMR. On the pathogenesis of diphtheritic paralysis. Q F Med 1917-18;11:191-204.

6 Walshe FMR. On the pathogenesis of diphtheritic paralysis. Part II. $Q \mathcal{F}$ Med 1918-19;12:14-31.

7 Fisher CM, Adams RD. Diphtheritic polyneuritis: a pathological study. F Neuropathol Exp Neurol 1956;15:243-67.

8 Lozhnikova CM, Pirogov VN, Piradov MA, et al. Diphtheritic polyneuropathy (DP): clinico-morphological study. Arkh Patol 1997;2:11-17. (In Russian.)

9 Solders G, Nennesmo I, Persson A. Diphtheritic neuropathy, an analysis based on muscle and nerve biopsy and repeated neurophysiological and autonomic function tests. f Neurol Neurosurg Psychiatry 1989;52:876-80.

10 Rolleston JD. Clinical observations on diphtheria paralysis. Part I. Practitioner 1904;2:597-623.

11 Créange A, Meyrignac C, Roualdes B, et al. Diphtheritic neuropathy. Muscle Nerve 1995;18:1460-3.

12 Kurdi A, Abdul-Kader M. Clinical and electrophysiological studies of diphtheritic neuritis in Jordan. F Neurol Sci 1979; 42:243-50.

3 Galazka AM, Robertson SE, Oblapenko GP. Resurgence of diphtheria. Eur f Epidemiol 1995;11:95-105.

14 Galazka AM, Robertson SE. Diphtheria: changing patterns in the developing world and the industrialised world. Eur 7 Epidemiol 1995;11:107-17.

15 Griskevica A. Diphtheria in Latvia: a description of the situation. Geneva: World Health Organisation, 1997:17.

16 Hardy IRB, Dittmann S, Sutter RW. Current situation and control strategies for resurgence of diphtheria in newly independent states of the former Soviet Union. Lancet 1996;347:1739-44.

17 Diphtheria epidemic: new independent states of former Diphtheria epidemic: new independent states of former
Soviet Union, 1990-4. Morbidity and Mortality Weekly Soviet Union, 1990-4.
Report 1995;44:177-81.

18 Kurtzhals JA, Kjeldsen K, Heron I, et al. Immunity against diphtheria and tetanus in human immunodeficiency virusinfected Danish men born 1950-9. APMIS 1992;100:8038.

19 Diphtheria in Russia: a reminder of risk. $\mathcal{F} A M A$ 1995;273: 1245

20 Kjeldsen K, Simonsen O, Heron I. Immunity against diphtheria $25-30$ years after primary vaccination in childhood. Lancet $1985 ;$ i: $900-2$.

21 Hughes RAC. Guillain-Barré syndrome. London: Springer Verlag, 1990.

22 Ropper AH, Wijdicks EFM, Truax BT. Guillain-Barré syndrome. Philadelphia: FA Davis, 1991.

23 Asbury AK, Cornblath DR. Assessment of current diagnostic criteria for Guillain-Barré syndrome. Ann Neurol 1990; 27(suppl):S21-4.

24 Diphtheria. Manual for the management and control of diphtheria in the European region. Copenhagen: World Health Organisation, 1994. (PP 18.) 
25 Hughes RAC, Newsom-Davis JM, Perkin GD, et al. Controlled trial of prednisolone in acute polyneuropathy. 1978;ii:750-3.

26 Van der Meché FGA, Schmitz PIM, and the Dutch Guillain-Barré Study Group. A randomised trial comparing intravenous immune globulin and plasma exchange in Guillain-Barré syndrome. N Engl f Med 1992;326:1123-9.

27 Prokopowicz D. Diphtheria: new threat or traditional disease. Przegl Epidemiol 1993;47:379-85. (In Polish.)

28 Liashenko UI, Velichko MA. The diagnostic and treatment characteristics of diphtheria in troop units and military medical institutions. Voenno Med Zh 1993;80:37-40. (In Russian.)

29 Adams RD, Victor M, Ropper AH. Principles of neurology. 6th ed. New York: McGraw-Hill, 1997:1207-8.

30 McDonald WI, Kocen RS. Diphtheritic neuropathy. In: Dyck PJ, Thomas PK, Griffin JW, eds. Peripheral neuropathy. 3rd ed. 1993:1412-17.

31 Maitra A, Bhattacharya SK, Das KP. Cerebral infarction in case of diphtheria. F Infect 1995;30:265.

32 Roche S, Stone S, Allen CMC, et al. Diphtheritic polyneuritis in an elderly woman: clinical and neurophysiological follow-up. Br F Clin Pract 1990;44:285-7.

citizens in the Russian Federation and Ukraine. FAMA 1995;273:1251-2.

34 Kazemi B, Tahernia AC, Zandian K. Motor nerve conduction in diphtheria and diphtheritic myocarditis. Arch Neurol 1973;29:104-6.

35 Hughes RAC. The concept and classification of GuillainBarré syndrome and related disorders. Rev Neurol (Paris) 1995;151:291-4.
36 Winner SJ, Grimley Evans J. Guillain-Barré syndrome in Oxfordshire: clinical features in relation to age. Age Ageing 993;22:164-70

37 McKhann GM. Guillain-Barré syndrome: clinical and therapeutic observations. Ann Neurol 1990;27(suppl):S1316.

38 Rees JH, Thompson RD, Smeeton NC, et al. Epidemiological study of Guillain-Barré syndrome in south east England. F Neurol Neurosurg Psychiatry 1998;64:74-7.

39 Plasma Exchange/Sandoglobulin Guillain-Barré Syndrome Trial Group. Randomised trial of plasma exchange, intravenous immunoglobulin, and combined treatments in Guillain-Barré syndrome. Lancet 1997;349:225-30.

40 McLeod JY, Pollard JD. Inflammatory demyelinating neuropathies. In: Kennard C. Recent advances in clinical neu

41 Burkhardt E, Eggleston C, Smith LW. Electrocardiographic changes and peripheral nerve palsies in toxic diphtheria. Am f Med Sci 1938;195:301-13.

42 Morales AR, Vichitbandha P, Chandruang $\mathrm{P}$, et al. Pathological features of cardiac conduction disturbances in Pathological features of cardiac conduction disturb

43 Burch GE Sun S-C, Sohal RS, et al. Diphtheritic myocarditis. A histochemical and electron microscopic study. $A m \mathcal{F}$ Cardiol 1968;21:261-7.

44 Kapustjan VA, Boldirev VV, Sedak JF. Complications in diphtheria. Ter Arkh 1993;65:75-7. (in Russian.)

45 Bethell DB, Dung NM, Loan HT, et al. Prognostic value of electrocardiographic monitoring of patients with severe diphtheria. Clin Infect Dis 1995;20:1259-65. 